\title{
Measuring Psychological Support for the Unemployed: The Case of Kakao NEET Project
}

\author{
Jaekwan Jeong, Kahui Park, Yaewon Hyun, and Daewon Kim* \\ Policy Team, Kakao Corp. \\ Jeju-si, Jeju-do, 63309, Korea \\ [e-mail: chris.jeong@kakaocorp.com, leah.park@kakaocorp.com, gem.hyun@kakaocorp.com, \\ ive.kim@kakaocorp.com] \\ ${ }^{*}$ Corresponding author: Daewon Kim
}

Received January 19, 2021; revised March 2, 2021; accepted March 12, 2021;

published April 30, 2021

\begin{abstract}
This paper attempts to investigate Korean youth Not in Education, Employment and Training (NEET) and how daily activities and community participation may influence their positive emotions and job search desire. First, we conducted a focus group interview with 16 NEETs who participated in the Kakao NEET Company project. The project allowed participants to experience employment by founding a virtual company in which each participant selected a daily activity to perform as part of the company's operations. Second, the interview responses were categorized and assigned emotional values using the card sorting technique and multidimensional analysis (MDS). A total of 11 emotional values were derived through this process. Finally, a social network analysis was conducted in order to measure the density of relations among the emotional values. Results suggest that immersion, confidence, belongingness were the three highest values evaluated by participants. Furthermore, network diagrams imply that the stronger participants perceived social support and belongingness with others, the stronger their responsibility grew, further leading them to establish steady goals. In particular, the high eigenvector score for "desire for job" suggests that emotional values are sequentially connected to the immersion-social support-responsibility-goal-job desire. This sequence suggests that digital services that are developed with the aim to enhance social values such as the Kakao NEET Project may engender motivation and confidence in youth NEETs. The overall results suggest that a systematic approach to policymaking should be considered in order to provide fundamental solutions and expand opportunities for social participation and emotional comfort, as social isolation due to low self-esteem has been reported as one of the reasons for NEETs' failure in the labor market.
\end{abstract}

Keywords: Employment, Kakao Project, NEET, Online Participation, Routine Activity 


\section{Introduction}

$\mathbf{Y}_{\mathrm{o}}$ outh unemployment and persistent uncertainty for youth continue to be important agendas of our society. The youth unemployment crisis is perceived by some to be an issue of the national employment policy and the social structure [1]. By others, youth unemployment is examined on the individual level, often perceived as a result of an overdependence on parents, an absence of financial independence or a lack of personal capacity [2]. In view of the individual factors related to youth unemployment, scholars attempt to provide an understanding with a focus on child development. For instance, one of the causes of youth unemployment proposed by scholars is that some young adults fail to mature out of the subordinate habits of their childhood and therefore, do not make the leap to independent adulthood. [3]. As such, in view of child development, mental immaturity can be one of the underlying causes of youth unemployment. However, such explanation may have its limitations in accounting for all generations of the NEET (Not in Education, Employment, or Training). First, it does not take into consideration the individual environmental factors, nor is it entirely relevant in the context of a rapidly changing society as there is no longer a clear distinction made for the various stages of life. Second, the age range of NEETs is expanding to people in their 30s. There has been an increase in the average age at which young people enter the labor market due to reasons such as higher education attainment or compulsory military service. Therefore, the perspective of evaluating child development may not accurately represent the unemployment phenomenon for job seekers at this age.

According to a report by Korea Employment Information Service, $76.5 \%$ of NEETs in Korea are active job seekers. The report assessed the primary reason that people quickly leave their jobs to "failure to adapt to the organization and job function (47.6\%)." Thus, simply providing job opportunities may not address the issue of unemployment in our society [4]. However, ongoing efforts to solve the youth unemployment problem have been heavily concentrated on increasing employment opportunities or increasing employment rates.

It is imperative to understand that merely increasing the number of job opportunities has long been weakly effective in providing a fundamental solution to the youth unemployment problem. According to Korea Economic Research Institute, the unemployment rate for university graduates in Korea who graduated between 2009 to 2019 increased by $0.7 \%$, from $5.0 \%$ to $5.7 \%$. Due to the increase in the unemployment rate, Korea's OECD employment rate ranking was 14th in 2009, but fell to the 28th in 2019 [5].

Another critical point is that while the overall employment rate has increased over the past 10 years, the youth employment rate is declining. One of the reasons for such failure of the national youth employment strategy is the lack of differentiated policies for each group of youth in the labor market; active job seekers, those who have given up their job-seeking activities, those who do not have a decent job, and non-regular workers. There is great need for an integrated policy based on a comprehensive understanding of young people's lives that supports youth to become self-reliant as healthy members of our society.

In this perspective, Nam divides the unemployed youth into job seekers and non-job seekers. According to Nam, the biggest problem of the Korean labor market is that the share of the NEET who are not active job seekers is gradually increasing. First, the younger generation, who have been pushed out of the job competition, do not seek for financial dependence or children which may result in an aging society with low birth rates. Second, young people lack self-esteem, withholding them to actively seek employment [6]. Because existing policies are focused on active job seekers, non-job seekers are inevitably excluded from benefits. Therefore, he emphasizes the importance of a multilateral system for non-job 
seekers.

Our society may recognize the NEET as the population that have been eliminated from competition. However, the NEET are not just young people who spend their pastime in indolence but may be viewed as a generation that is struggling with "broken legs." They are assumably in a life stage where they are contemplating about what to do while being "burned out." What if young people were to engage in activities that trigger motivation? What psychological changes will the activities cause in them? Therefore, this study first aims to investigate the positive psychological changes that may be induced by engaging the NEET in daily tasks and routines. This study then examines how the psychological changes affect NEETs in their job-seeking desire. Based on the results, this study attempts to derive implications and propose future direction in supporting youth in the labor market. Lastly, this study explores whether the digital services provided by digital enterprises may contribute to the society and enhance social values.

\section{Related Work}

\subsection{Defining NEET}

The term, NEET (Not in Education, Employment or Training), generally refers to those who are unemployed and are not willing to receive education or vocational training. This term was first introduced in a report by the Social Exclusion Unit of the United Kingdom [7]. Although this report was originally written in view of adolescents aged 16 to 18 years old, the concept of the NEET population expanded to the discussion of youth employment. In most European and Western countries, the NEET refer to young people between the ages of 16 to 24, who are currently unemployed and do not engage in other activities [8]. According to Powell, there are roughly 783,000 people that make up the UK NEET population [9].

Unlike the UK and Western countries, the NEET in Korea refer to a group with a broader age range. In general, considering the high rate of high school enrollment in Korea, adolescents over 18 years old are considered as NEET. The definition of Korean NEET also encompasses the generation of people in their mid-30s, considering that Koreans enter the labor market much later than those in other countries do due to reasons such as higher education attainment or compulsory military service. For instance, Nam defined the NEET in Korea as young people between the ages of 18 to 34, who are (1) not attending an educational institution, academy, or vocational training institution, (2) not currently working, (3) not a home-maker or parent, and (4) single [10].

Another difference between Western countries and Korea in defining the concept of the NEET is whether the traditional definition of unemployed groups should be included. Some studies exclude unemployed groups from the NEET [11,12] and other studies include such groups by reconceptualizing Korean NEET [13]. As the concept of NEET differs from the traditional definition of unemployed groups, this has been widely debated. According to research in the UK, where the concept of NEET has originated, the NEET refer to those who are not seeking for employment due to lack of desire. However, this classification including the voluntary unemployed groups is deemed inapplicable in the Korean context.

In Korea, willingness to find a job is not a major factor in determining employment. Hence, unemployed people who are actively seeking a job should be also included in conceptualizing Korean NEET. Later studies mainly divide the NEET into two types: job-seeking and non-job seeking [10]. According to a 2017 OECD report, the proportion of non-job seeking NEET is $18.4 \%$ in Korea, exceeding the average $13.4 \%$ of 36 countries [14]. Another research shows 
that the proportion of job-seeking NEET is $76.5 \%$, which is significantly higher than that of non-job seeking NEET (23.5\%). Also, $41.4 \%$ of the job seeking NEET were found to have never gotten a job after graduation [15].

\subsection{Types and Characteristics of NEET}

Apart from observing age groups and people's willingness to find a job, various attempts have been made to define and classify the NEET. In the UK, Eurofound (2012) suggested 5 types of NEET as (1) the conventionally unemployed group, (2) the unavailable group who became the NEET due to housework, family care, illness or disability, (3) the disengaged group who are considered to have a lack of ability, low-motivation or maladjustment to society, (4) the opportunity-seekers who are waiting for better chances, and (5) the voluntary NEET. [16]

One of the early classifications of the NEET in Korea were made in 2007 by Kum et al. (2007), by distinguishing youth NEET into (1) the family worker type (unpaid family worker or house worker), (2) traditional youth unemployment, (3) trapped NEET preparing for an examination or license, and (4) the reality avoidance type [13]. When people are unemployed because they are preparing for an examination or license, they are considered as trapped NEET, which is the equivalent to the opportunity seekers found in the Eurofound classification.

Later, Lee et al. (2010) applied qualitative methods in order to define Korean NEET. Researchers recognized the NEET problem as a career obstacle and conducted in-depth interviews of people who were NEET at the time or had previous experience. Based on the interview analysis, they suggested four types of Korean NEET as (1) the introspective atrophy type, (2) the dreaming fritter type, (3) the career immature type, and (4) the examination type. Due to their introverted nature, the introverted atrophy type engages in work that can minimize social relations and stays on the periphery of the labor market. The dreaming fritter type tends to avoid discipline and desires to find a job to realize self-actualization. In the case of the career immature type, their discrepancy in job-seeking level is the main cause of unemployment. The examination type places the highest importance on job security, thus hesitates to find a job. [15]

In another study, Kim (2017) suggested the types of the NEET as those who are (1) preparing for employment, (2) preparing for education, (3) engaging in housework or care, (4) giving up or resting, and (4) battling disease and/or disorder. The preparing for employment type refers to people who are preparing for employment. The preparing for education type refers to those preparing to attain higher education. The engaging in housework or care type consists of people who temporarily give up their jobs in order to take care of the household or family members. The giving up or resting type refers to the NEET who give up employment due to a lack of ability or lack of motivation. The last type, the battling disease and/or disorder type refers to those who have a mental or physical disability and/or disease that makes it difficult for them to conduct daily activities [17].

Joo and Joo (2017) classified four types of NEET as (1) job-seeking (11\%), (2) opportunity-seeking (4.6\%), (3) disconnected (0.4\%), and (4) abandoned (84\%). They content that there should be efforts to incorporate the opportunity-seeking type of NEET who are willing to get a job but are not actively seeking one and the abandoned type of NEET who do not intend to get a job and do not look for a job, into society. However, the current youth employment policy is tailored to only $11 \%$ of the job-seeking type and therefore, needs improvement [18].

\subsection{The Problem of Studying NEET}

As such, the NEET, as a critical population for solving youth unemployment in Korean society, 
has received attention in the fields of pedagogy and vocational education. However, a large number of studies have been centered upon quantitative studies, such as conceptual studies examining the definition and characteristics of Korean-style NEET and the correlation between their demographic characteristics. Such research has its advantages as it can illustrate the reality of the NEET in Korean society and may facilitate analyses on the labor market. However, it does not surmount its limitations in understanding what difficulties and obstacles the NEET face in job-seeking.

Therefore, several researchers have conducted qualitative interviews with the NEET to identify the difficulties that the NEET face in the attempt to categorize them. For instance, in Cho et al. (2018)'s interviews of the NEET, they found that the negative experiences the NEET underwent in their past or current workplaces led to decreased self-esteem, increased helplessness towards failure, and a reinforced vicious cycle in which the NEET face greater difficulty due to their passive attitudes [19].

Other researchers have paid attention to groups who are not clear about their intention to work and do not seek employment. These group are defined as the reality avoidance type [13], the introspective atrophy type [15] and the exhausted type [20]. Overall, research concludes that the NEET who do not succeed in finding a job experience a loss of confidence and lack of desire.

While previous literature suggests the lack of confidence and desire as one of the major causes of unemployment, there are empirical studies that provide substantial evidence that support this suggestion. For instance, there is scarce research that explores the negative psychological factors commonly shared by the NEETs and what is needed to eliminate these negative psychological factors and provide positive conditions.

On these grounds, this study investigates whether participatory activities and communication among the NEET population will be able to reduce their negative emotions and increase positivity in their perceptions. For the study, Kakao's NEET Company project was selected as a platform to observe participatory activities and communication among the NEET and evaluated through interviews of the participants.

Based on previous research, two questions are posed for the young people participating in the NEET Company project.

RQ1: What are the key values gained by participants through the project?

RQ2: How does each value relate to the participants' perception?

\subsection{The NEET Company Project by Kakao}

The NEET Company is a virtual company founded by the non-profit startup organization, NEET Life, and co-operated with Kakao's Kakao Project 100 (https://project100.kakao.com/). The NEET Company's purpose is to revitalize the life rhythm of the NEET and support them in their transition from unemployment. The operation of the project was simple. Participants chose an activity that was to be repeated daily and that could contribute to long term change in their lives. During the hours of the workday, participants were asked to take a photo proving that they completed the committed daily task and upload the photo to share with other participants. This process was called, "daily mission." Once they uploaded the photos, participants provided each other with feedback on their activities. They met once a month to check their achievements and encourage others to accomplish their goals. At the end of the project, they shared their final results and perceived changes induced by the project in an exhibition.

This year, 98 participants, ranging from 18 to 39 years to old completed the project. The project was conducted from March 23, 2020 to June 30, 2020. 


\section{Research Approach}

Previous research indicate that not only economic assistance, but also psychological and emotional support may be necessary to motivate the NEET to willingly remove themselves from their current situations and to participate in socially productive activity. Yet, there is a lack of literature analyzing the causes of the NEET expressing low self-confidence and desire, and the factors that could engender the NEET to overcome negative experiences. In addition, there is scarce prior research observing the long-term experiences of solidarity shared among the NEETs acting as a mediator to solve the NEET issue.

Through a step-by-step process, this research, broadly attempt to explore the social cognitions of the participants of the NEET Company Project, such as their motivations, psychological and emotional values induced from the activities. The research also derives keywords from the participants' experiences and identifies a systematic keyword structure that may serve in understanding the NEET phenomenon.

\subsection{Focus Group Interview (FGI)}

The first step of research began with Focus Group Interviews (FGI) lasting three-hours each. FGI was the research method of choice in order to collect data on participants' interactions and discussions on topics proposed by the interviewer. Each participants' original agenda was shared and reviewed with other participants in the group interviews, then revised based on their collective understanding of the topic [21].

A total of sixteen interviewees were sampled from those who successfully completed the NEET Company project. Ten out of the sixteen interviewees were male and six were female. Nine interviewees were job seekers and the other seven interviewees were non-job seekers. Nine interviewees had prior working experience while the other seven interviewees had no experience. The interviewees' ages ranged from 21 to 34 years old. In order for the interviewees to have equal opportunity to voice their opinions and interact with other interviewees, they were divided into two groups. While random group distribution process was conducted, interviewees' demographic information such as gender, age, job experiences and job search status were considered.

Both FGIs were held on the same day, one in the morning, followed by the next interview. By conducting interviews in a consecutive manner, this prevented the first group of FGI participants to release any information to the latter group of participants. The two FGIs were three hours long with two moderators each: the main moderator (male), and an assistant (female).

The main purpose of the FGI was to explore how online social support and the concept of perceived belongingness would influence the participants' wellbeing. As Fig. 1 illustrates, the 5 -stage concept mapping process by Kane and Trochim (2007) was applied in order to extract key values that the interviewees gained from the NEET Company project [22]. Before the interview started, participants were informed of the purpose and subject of the interview. The interview was initiated with a broad question asked by the moderator, "What does the NEET Company project mean to you?" This first question would allow the interviewees to freely express their opinions and voice their spontaneous thoughts. Based on their responses, the moderation asked follow-up questions such as "their reasons for participating" and "what they liked and disliked," in the second step of the process. 


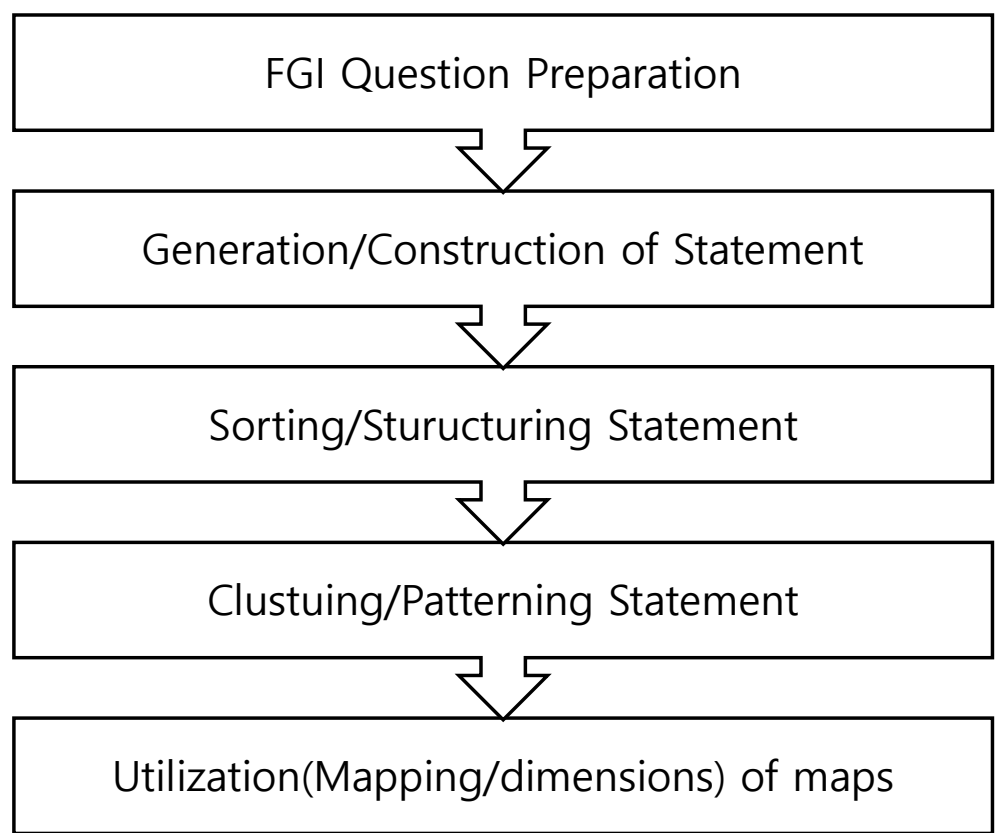

Fig. 1. Concept Mapping Process. Reconstructed from Kane and Trochim (2007)

Next, followed the third step of the process in which the two moderators carefully reviewed the entire transcript, examining it sentence-by-sentence. The two moderators, then extracted 120 value statements from the transcript, based on the frequency of appearance and its importance. After numerous discussions, $81 \mathrm{key}$ statements were finally deduced. Refer to Appendix 1.

\subsection{Card Sorting}

The fourth stage was to cluster the 81 statements into groups for evaluation. A card sorting method was applied in this stage. The card sorting method is widely used in various fields including software design, UX, psychology and sociology. It serves as a useful tool to elicit conceptual values from cognitive ideas [23]. In this research, the card sorting method in this research was selected for two reasons. First, the card sorting method is an effective technique in interviews where interviewees independently establish conceptual values, by recalling the original entity of their interview responses [24]. Second, it allows participants to compare and contrast theirs' and others' values and collectively establish a value hierarchy [25].

FGI participants met in the following week for this process. First, participants read through the 81 statements to confirm that each statement was clear and accurate, then evaluated them using the 7-point Likert scale, from 1: strongly disagree; to 7: strongly agree. The scores given to each statement can be examined in Appendix 1. Second, they were asked to classify the 81 statements into several categories based on the similarity of the statements' psychological value. Participants were asked to assort and place closely-related statements into the categories, given that each group were assigned at least two statements and that each statement belonged to only one category. After the sorting process was completed, the participants were asked to select and write down the items and values of each category on a separate piece of paper. While writing, participants were asked to give a name to each item in the categories and a unique number to the statement of each item. An example of the paper is illustrated in Fig. 2. The entire card sorting process lasted three hours. 


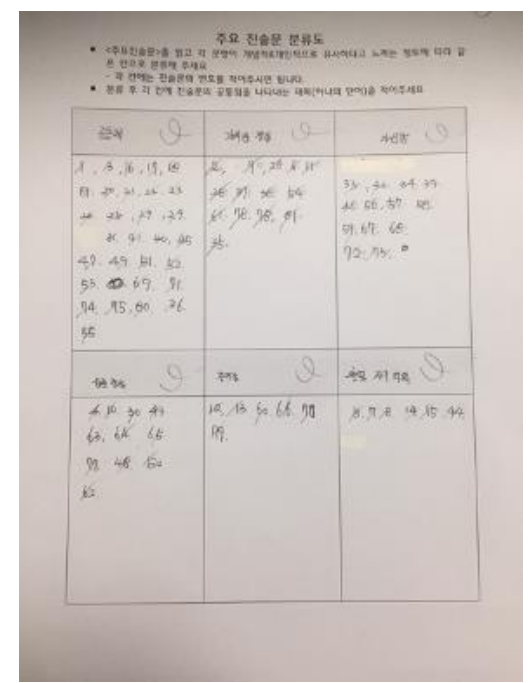

Fig. 2. Example of participants' card sorting result

\subsection{Multi-Dimensional Analysis (MDS)}

The fourth stage was to cluster the 81 statements into the number of groups and to evaluate them. Since the purpose of this stage was to structure and form a pattern of the participants' response as a whole, individual classification results were summed as a single category. In order to generate the category, a multi-dimensional analysis based on the inter-attribute similarity matrix was applied. This analysis was appropriate for this study in view of the three components it requires, (1) data extraction using free word association, (2) content analysis (or coding) of concepts to represent social cognition, and (3) similarity analysis to identify shared-concepts [26].

In a group similarity matrix, individual responses from the participants were coded as "1," where two statements belong to the same category, or " 0 ," where two statements belong to different categories. The coded group similarity matrix was analyzed with $\mathrm{R}$ programming. In this process, multi-dimensional analysis (MDS) and hierarchical cluster analysis were conducted in order to divide and subdivide the data into consistent clusters.

\subsection{Mind Mapping}

After key values were extracted from the multi-dimensional analysis, two researchers coded each sentence of the interview script. Because a coding scheme could not be created until the result of the MDS was produced, this study adopted the "open coding procedure" as suggested by Jung, Pawlowski, and Willey-Patton (2009) [27]. The codebook was created based on the collected data of the study. As a result, the MDS analysis used to decide the coding items produced 11 items.

When two values were identified in an interviewees" remark, it was coded as "1" on an inter-attribute similarity matrix. The adjacency matrix represents the connection between the identified values. The standard measure of associative value was evaluated by the sum of similarity and correlativeness. First, an inter-attribute similarity matrix (IAS matrix) was constructed. The coefficient of each cell was used to represent the degree of co-occurrence (proximity) to a pair of attributes as given by Jaccard's similarity coefficient. The higher the value of the Jacquard similarity coefficient, the greater would be the correlation of values [28]. Based on the Jacquard similarity coefficient scores, a network analysis was conducted in order 
to observe the relationship between the key values. This study calculated the relative importance of node values by calculating four centrality indices: Indegree Centrality, Incloseness centrality, Betweeness centrality, and Eighevector centrality. Since there were eleven items derived from the multi-dimensional analysis, eleven nodes reciprocal to the items were created (refer to Results).

When the interviewee mentioned two or more values during the interview, this signified a relationship between the nodes, creating a link between the nodes in the network analysis. This was expressed as an edge. There are several ways to express the relative importance of each value (node) in a network map composed of numerous nodes and edges. This study applied four methods to measuring their centrality.

Degree Centrality is calculated as the number of edges connected to one node. In this study, the centrality was calculated based on the support of the subsequent value centering on the value mentioned earlier, so the In-degree centrality from other nodes was summed. In general, centrality calculations based on the In-degree indicate the popularity of the node and centrality calculations based on the Out-degree indicate the influence of the node. The criteria for calculating the In-degree centrality are as follows:

$$
C_{-}\{i\}(i)=\operatorname{sum}_{-}\{j=1\}^{\wedge}\{n\} x_{-}\{j i\}
$$

Closeness Centrality assumes that the more important nodes are, the shorter the edge path to other nodes. As one node (value) occupies an important position in the relationship between nodes, the node is located at the center of the network relationship diagram. Thus, the sum of the shortest distances to other nodes will decrease. When calculating centrality from this assumption, it can be assumed that the higher the centrality node, the shorter the speed of information going to other nodes and the greatest influence. The criteria for calculating the proximity center of gravity are as follows:

$$
\mathrm{CC}(\mathrm{i})=\{\mathrm{N}-1\} \text { over }\left\{\operatorname{sum}_{-}\{\mathrm{i}\}^{\wedge}\{.\} \mathrm{d}(\mathrm{i}, \mathrm{j})\right\}
$$

Betweeness Centrality is an index similar to proximity centrality, but it measures the importance of whether the node plays a role as a relay. In other words, where the node A and the node $\mathrm{C}$ are connected, the center of mediation of $\mathrm{B}$ increases, and the more it is located on the connection line between nodes, the higher the center of mediation. The criteria for calculating mediation center of gravity are as follows:

$$
C_{-}\{B\}\left(n_{-}\{i\}\right)=\operatorname{sum}_{-}\{j<\mathrm{k}\}{ }^{\wedge}\{\} g_{-}\{j k\}\left(n_{-}\{i\}\right) / g_{-}\{j k\}
$$

Eigenvector Centrality is calculated by putting a weight on the degree of connection with important nodes rather than the number of connected nodes, unlike a method in which the connection center measures the number of connected nodes to be measured. The eigenvector centrality is calculated by Google based on a concept similar to PageRank, and the calculation criteria are as follows:

$$
\begin{array}{r}
\left.\mathrm{CE}(\mathrm{i})=\{1\} \text { over }\{\text { lambda }\} \text { sum } \_ \text {j epsilon } M(\mathrm{i})\right\}^{\wedge}\{\mathrm{INF}\} \mathrm{CEj} \\
\left.=\{1\} \text { over }\{\text { lambda }\} \text { sum } \_\mathrm{j}=1\right\}^{\wedge}\{\mathrm{N}\} \text { Ai,jxj }
\end{array}
$$




\section{Results}

The first research question investigates the key values that participants gained from engaging in daily and routine activities during the Kakao NEET Company project. The first stage of research were the focus group interviews on the experiences of sixteen interviewees, from which their responses were summarized into 81 key statements. See Appendix 1.

The 81 statements demonstrate various insight on the projects and the experiences of the participants, ranging from psychological factors such as "responsibility ("I felt sorry to the others when I didn't work hard, $\mathrm{M}=4.375$ ")", relational factors such as "social support ("As time went on, I developed a bond with other people, $\mathrm{M}=5.06$ ")", to behavioral factors such as "routine ("I became more stable, M=5.50)".

The second stage involved two steps. First, the interviewees evaluated the importance of the 8 statement on a 7-point Likert scale. Second, the interviewees classified the statements into several categories. After a multi-dimensional analysis of each interviewee's perceived values of the project, the 81 statements were classified according to 11 categories, presented in order of highest to lowest scores.

The highest-scoring category was "Immersion (M=6.12)," containing seven statements. "I was deeply immersed in this activity $(\mathrm{M}=6.00)$ ), "It was refreshing to my life $(\mathrm{M}=6.19)$ )", "There was a sense of accomplishment $(\mathrm{M}=6.41)$ ", "I was satisfied with this project $(\mathrm{M}=6.44)$ ", "This activity was fun $(\mathrm{M}=6.19)$ ", "The more I worked, the more rewarding it felt $(\mathrm{M}=5.81)$ ", and "I feel a sense of self-fulfillment $(\mathrm{M}=6.00)$ ".

The second highest-scoring category was "Confidence $(M=6.12)$ ". Statements in this category include, "I gained self-esteem (M=6.38)", "I felt like I was improving $(\mathrm{M}=6.00)$ ", "I was able to look back on myself $(\mathrm{M}=5.88)$ ", "I have developed expectations for myself $(\mathrm{M}=5.75)$ ", "I have confidence in life $(\mathrm{M}=5.25)$ ", "I feel like I can do anything $(\mathrm{M}=5.06)$ ", "I found my strength $(\mathrm{M}=5.00)$ ", "I felt generosity towards myself $(\mathrm{M}=4.63)$ ", and "I began to love myself $(\mathrm{M}=5.81)$ ". Following suite, the category, "Belongingness $(\mathrm{M}=5.27)$ ", indicates perceived connectedness with other participants. Statements in this category are, "I feel a sense of belonging ( $\mathrm{M}=6.21)$ ", "It was fun to be with other people $(\mathrm{M}=5.75)$ ". "(Interaction with other people) gave me emotional stability $(\mathrm{M}=5.13)$ ", and "The daily mission helped me feel a sense of belongingness $(\mathrm{M}=4.00)$ "

The next category, 'Routine of Life $(M=5.15)$ ' consists of statements that described the participants' behavioral changes. The statements are "There was a big change through an accumulation of the small things $(M=5.63)$ ", "I developed a regular habit $(M=5.38)$ ", "I became more stable $(\mathrm{M}=5.50)$ ", "My daily life did not collapse $(\mathrm{M}=5.50)$ ", "A life routine has been formed $(\mathrm{M}=5.25)$ ", My attitude towards life has changed $(\mathrm{M}=4.75)$ ", and "I have plans for everything $(\mathrm{M}=4.07)$."

The fifth category extracted was "Social Support $(M=5.00)$ ". This category concerns statements that supported mutual bonding for social support. The 11 statements in this category were "We cheered for each other (M=5.95)", "Others were a positive stimulus ( $M=5.93)$ ", "As time went on, I developed a bond with people $(\mathrm{M}=5.06)$ ", "I felt like we were together $(\mathrm{M}=5.06)$ ", "I was motivated by other people's activities $(\mathrm{M}=5.06)$ ", "The encouragement of others motivated me $(\mathrm{M}=5.00)$ ", "Others praised me $(\mathrm{M}=4.81)$ ", "I wanted someone to be interested in what I was doing $(\mathrm{M}=4.81)$ ", "We helped each other $(\mathrm{M}=4.69)$ ", "I wanted to be recognized by others $(\mathrm{M}=4.38)$ ", and "I cooperated with other participants $(\mathrm{M}=4.25)$."

According to the results, this project also positively affected the participants' ability to set goals. The following category, "Goal (M=4.97)" includes 9 statements; "I have passion in life $(\mathrm{M}=5.75)$ ", "I was able to achieve my goal $(\mathrm{M}=5.75)$ ", "I have a sense of responsibility $(\mathrm{M}=5.50)$ ", "I have the spirit for challenge $(\mathrm{M}=5.44)$ ", "A vague dream has become a reality 
$(\mathrm{M}=5.13)$ ", "I developed a habit of setting goals for work ( $\mathrm{M}=4.63)$ ", "The direction for my life has become clearer $(\mathrm{M}=4.25)$ ", "When I have a goal, I can share it with others $(\mathrm{M}=4.19)$ ", and "I wanted to present the results at this opportunity ( $\mathrm{M}=5.15)$ "

The next category, "New relationships $(M=4.82)$ ", shares commonalities with the previous category, "Social Support" in that it describes the participants' relationships with others. However, while the former item refers to the solidarity fostered among participants, the latter value refers to the desire to expand and create new relationships beyond the project. Statements in this category are, "I was able to meet new people $(\mathrm{M}=5.94)$ ", "I wanted to know more about other people $(\mathrm{M}=5.81)$ ", "I wanted to establish a new relationship ( $\mathrm{M}=5.25)$ ", "This became a motive for social activities ( $\mathrm{M}=4.69)$ ", "I came to understand others $(\mathrm{M}=4.56)$ ", "I wanted to live the life that society needs $(\mathrm{M}=4.31)$ ". "I have developed generosity towards others $(\mathrm{M}=4.00)$ ", "I became considerate of others $(\mathrm{M}=3.75)$ "

The next category, "Viewpoint $(\mathrm{M}=4.69)$ ", deals with statements that changes interviewees' ways of thinking. Five statements in this category explain how the project affected their point of view on life. They are "My daily life felt valuable $(\mathrm{M}=5.63)$ ", "I wanted to do more things $(\mathrm{M}=5.44)$, "My values were broadened $(\mathrm{M}=4.81)$ ", "My meaning of life has matured $(\mathrm{M}=3.88)$ ", and "I feel a sense of value $(\mathrm{M}=3.69)$ ".

"Responsibility $(\mathrm{M}=4.65)$ " was also listed as one of perceived value categories that the interviewees gained through the project. In this category, the nine statements include "I neglected to participate and did not want to harm others $(\mathrm{M}=5.56)$ ", "I gelt guilty not doing the daily mission $(\mathrm{M}=5.50)$ ", "I made up my mind to work hard $(\mathrm{M}=5.19)$ ", "I had promised to accomplish it with others $(\mathrm{M}=4.63)$ ", "There was pressure to complete the project $(\mathrm{M}=4.63)$ ", "I felt sorry to the others when I didn't work hard (M=4.38)", "There was pressure on the daily mission ( $\mathrm{M}=4.38)$ ". "I felt isolated when I skipped activities $(\mathrm{M}=3.88)$ ", and "I felt stressed $(\mathrm{M}=3.69)$ ".

Although most of the activities were conducted online, participants often participated in regular activities offline. Interviewees evaluated online and offline activities as one of the values of the project. The "On/Offline $(\mathrm{M}=3.95)$ " category consists of four statements; "Offline activities increased participation $(\mathrm{M}=4.43)$ ", "More offline activities needed to be added ( $\mathrm{M}=4.19)$ ", "More online activities needed to be added $(\mathrm{M}=3.06)$ ", "I acted different online and offline ( $\mathrm{M}=2.56)$ ".

The last category consists of statements on how the participants' "Desire for Job (M=3.79)" changed because of this project. Although this item did not score as high compared to other values, interviewees considered the desire for a job as one of the changes induced by this project. The statements assigned to this category are "Through this activity, I have a desire to find a job (M=4.43)", "Based on this experience, I think I will be able to do better at work in the future (M=4.19)", "The concept of an ideal job for me has changed ( $M=4.19)$ ), "I have confidence in finding a job $(\mathrm{M}=3.44)$ ", "I gained insight on finding a job and on company life $(\mathrm{M}=2.69)$ ". The overall list of category items and statements in each item can be found in Table 1. 
Table 1. Interviewees' perceived values and statements of the NEET project

\begin{tabular}{|c|c|}
\hline \multirow{2}{*}{$\begin{array}{l}\text { Categories } \\
\text { Immersion }\end{array}$} & \multirow{2}{*}{$\frac{\text { Score }}{\mathrm{N}=7, \mathrm{M}=6.12}$} \\
\hline & \\
\hline 1. I was deeply immersed in this activity. & 6.00 \\
\hline 2. It was refreshing to my life. & 6.19 \\
\hline 3. There was a sense of accomplishment. & 6.41 \\
\hline 4. I was satisfied with this project. & 6.44 \\
\hline 5. This activity was fun. & 6.19 \\
\hline 6. The more I worked, the more rewarding it felt. & 5.81 \\
\hline 7. I feel a sense of self-fulfillment. & 5.81 \\
\hline Confidence & $\mathrm{N}=9, \mathrm{M}=5.43$ \\
\hline 1. I gained self-esteem. & 6.38 \\
\hline 2. I felt like I was improving. & 6.00 \\
\hline 3. I was able to look back on myself. & 5.88 \\
\hline 4. I have developed expectations for myself. & 5.75 \\
\hline 5. I have confidence in life. & 5.25 \\
\hline 6. I feel like I can do anything. & 5.06 \\
\hline 7. I found my strength. & 5.00 \\
\hline 8. I felt generosity towards myself. & 4.63 \\
\hline 9. I began to love myself. & 4.56 \\
\hline Belongingness & $\mathrm{N}=4, \mathrm{M}=5.27$ \\
\hline 1. I feel a sense of belonging. & 6.21 \\
\hline 2. It was fun to be with other people. & 5.75 \\
\hline 3. (Interaction with other people) gave me emotional stability. & 5.13 \\
\hline 4. The daily mission helped me feel a sense of belonging. & 4.00 \\
\hline Routine of Life & $\mathrm{N}=7, \mathrm{M}=5.15$ \\
\hline $\begin{array}{l}\text { 1. There was a big change through an accumulation of the small } \\
\text { things. }\end{array}$ & 5.63 \\
\hline 2. I developed a regular habit. & 5.38 \\
\hline 3. I became more stable. & 5.50 \\
\hline 4. My daily life did not collapse. & 5.50 \\
\hline 5. A life routine has been formed. & 5.25 \\
\hline 6. My attitude towards life has changed. & 4.75 \\
\hline 7. I have plans for everything. & 4.07 \\
\hline Social Support & $\mathrm{N}=11, \mathrm{M}=5.00$ \\
\hline 1. We cheered for each other. & 5.95 \\
\hline 2. Others were a positive stimulus. & 5.93 \\
\hline 3. As time went on, I developed a bond with people. & 5.06 \\
\hline 4. I felt like we were together. & 5.06 \\
\hline 5. I was motivated by other people's activities. & 5.06 \\
\hline 6. The encouragement of others motivated me. & 5.00 \\
\hline 7. Others praised me. & 4.81 \\
\hline 8. I wanted someone to be interested in what I was doing. & 4.81 \\
\hline 9. We helped each other. & 4.69 \\
\hline 10. I wanted to be recognized by others. & 4.38 \\
\hline 11. I cooperated with other participants. & 4.25 \\
\hline Goal & $\mathrm{N}=9, \mathrm{M}=4.97$ \\
\hline 1. I have passion in life. & 5.75 \\
\hline 2. I was able to achieve my goal. & 5.75 \\
\hline 3. I have a sense of responsibility. & 5.5 \\
\hline 4. I have the spirit for challenge. & 5.44 \\
\hline 5. A vague dream has become a reality. & 5.13 \\
\hline 6. I developed a habit of setting goals for work. & 4.63 \\
\hline
\end{tabular}




\begin{tabular}{|c|c|}
\hline $\begin{array}{l}\text { 7. The direction for my life has become clearer. } \\
\text { 8. When I have a goal, I can share it with others. } \\
\text { 9. I wanted to present the results at this opportunity. }\end{array}$ & $\begin{array}{l}4.25 \\
4.19 \\
4.06\end{array}$ \\
\hline New Relationships & $\mathrm{N}=8, \mathrm{M}=4.82$ \\
\hline 1. I was able to meet new people. & 5.94 \\
\hline 2. I wanted to know more about other people. & 5.81 \\
\hline 3. I wanted to establish a new relationship. & 5.25 \\
\hline 4. This became a motive for social activities. & 4.69 \\
\hline 5. I came to understand others. & 4.56 \\
\hline 6. I wanted to live the life that society needs. & 4.31 \\
\hline 7. I have developed generosity towards others. & 4.00 \\
\hline 8. I became considerate of others. & 3.75 \\
\hline Viewpoint & $\mathrm{N}=5, \mathrm{M}=4.69$ \\
\hline 1. My daily life felt valuable. & 5.63 \\
\hline 2. I wanted to do more things. & 5.44 \\
\hline 3. My values were broadened. & 4.81 \\
\hline 4. My meaning of life has matured. & 3.88 \\
\hline 5. I feel a sense of value. & 3.69 \\
\hline Responsibility & $\mathrm{N}=9, \mathrm{M}=4.65$ \\
\hline 1. I neglected to participate and did not want to harm others. & 5.56 \\
\hline 2. I felt guilty not doing the daily mission. & 5.50 \\
\hline 3. I made up my mind to work hard. & 5.19 \\
\hline 4. I had promised to accomplish it with others. & 4.63 \\
\hline 5. There was pressure to complete the project. & 4.63 \\
\hline 6. I felt sorry to the others when I didn't work hard. & 4.38 \\
\hline 7. There was pressure on the daily mission. & 4.38 \\
\hline 8. I felt isolated when I skipped activities. & 3.88 \\
\hline 9. I felt stressed. & 3.69 \\
\hline On/Offline & $\mathrm{N}=4, \mathrm{M}=3.95$ \\
\hline 1. Offline activities increased participation. & 5.31 \\
\hline 2. More offline activities needed to be added. & 4.88 \\
\hline 3. More offline activities needed to be added. & 3.06 \\
\hline 4. I was different online and offline. & 2.56 \\
\hline Desire for Job & $\mathrm{N}=5, \mathrm{M}=3.79$ \\
\hline 1. Through this activity, I have a desire to find a job. & 4.43 \\
\hline $\begin{array}{l}\text { 2. Based on this experience, I think I will be able to do better at } \\
\text { work in the future. }\end{array}$ & 4.19 \\
\hline 3. The concept of an ideal job for me has changed. & 4.19 \\
\hline 4. I have confidence in finding a job. & 3.44 \\
\hline 5. I gained insight on finding a job and on company life. & 2.69 \\
\hline
\end{tabular}

The second research question examines the correlation of the values found in the previous step. Comparing four centrality scores, it is worthwhile to note that the value, "Immersion" is placed on the center of the network. Immersion plays a key role in indegree, in-closeness, and betweenness centrality, signifying that immersion is the most frequently connected to other values when interviewees are discussed. Also, it is assumed that immersion is a prerequisite in forming the other perceived values in this project.

"Goal" and "Responsibility" were also core values of the project. Interviewees perceived that the NEET project provided an opportunity to set clear goals and that the motivation for participants to maintain their goals stemmed from responsibility. It is clear that "Belongingness" plays the role of a mediator in the goal-responsibility relationship. As Table 2 demonstrates, while goal-responsibility-belongingness are highly correlated to each other, 
the eigenvector score of "Belongingness" is higher than other centrality scores. This implies that the "Belongingness" is in close proximity with other important values.

When observing centrality score distributions (see Table 2), there are values of which one of centrality scores is noticeably higher than other. For instance, the in-closeness score for "Social Support (0.513)" is the second highest-scored among the 11 values, while other scores are relatively low. This means that social support among participants plays an important role in shaping different values. In other words, it can be recognized that when participants talked about other values, they spoke more frequently in direct connection with words related to "Social Support."

Another observation can be found in the centrality scores for the "Desire for Job" values. It is observed that although the other scores "Desire for Job" are among the lowest, its eigenvector score is the highest among values. That this value is not highly connected to other nodes and is not located at the center of the network despite its high eigenvector score implies that the interviewee mentioned important values frequently when speaking about the "Desire for Job".

Table 2. Centrality score for interviewees' perceived values

\begin{tabular}{|c|c|c|c|c|}
\hline Values & Indegree & In-closeness & Betweenness & Eigenvector \\
\hline \hline Immersion & 0.383 & 0.537 & 0.039 & 0.385 \\
\hline Goal & 0.349 & 0.398 & 0.024 & 0.666 \\
\hline Responsibility & 0.234 & 0.513 & 0.024 & 0.497 \\
\hline Belongingness & 0.189 & 0.398 & 0.013 & 0.416 \\
\hline Confidence & 0.183 & 0.324 & 0.012 & 0.432 \\
\hline Social Support & 0.177 & 0.532 & 0.009 & 0.380 \\
\hline Viewpoint & 0.160 & 0.354 & 0.008 & 0.409 \\
\hline New Relationship & 0.149 & 0.379 & 0.007 & 0.364 \\
\hline Routine of Life & 0.131 & 0.374 & 0.006 & 0.371 \\
\hline Desire for Job & 0.114 & 0.389 & 0.006 & 0.854 \\
\hline On/Offline & 0.080 & 0.395 & 0.006 & 0.354 \\
\hline
\end{tabular}

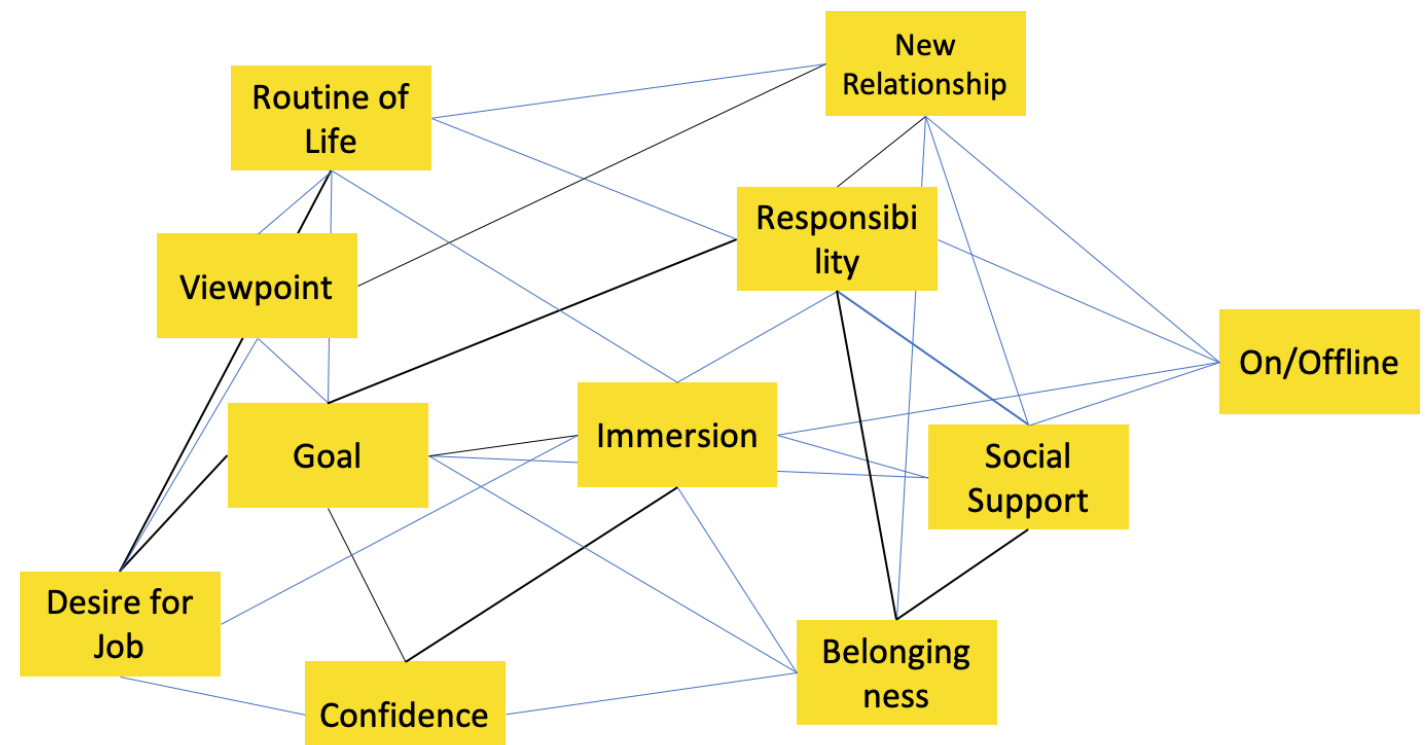

Fig. 3. Social network structure of interviewees' perceived value 


\section{Discussion and Conclusion}

The results of this study enable us to discover and categorize the key values that the NEET gained through the NEET Company project activities promoting social participation and communication. Although not included in the research results, during the interview, the participants were asked to map their mental state with keywords, dividing them into phases before, during, and after the NEET Company project. Before participating in the NEET company project, participants described themselves as bored, helpless, and frustrated who were unable to carry out plans. After completing the project, participants self-reported themselves with heightened responsibility and confidence.

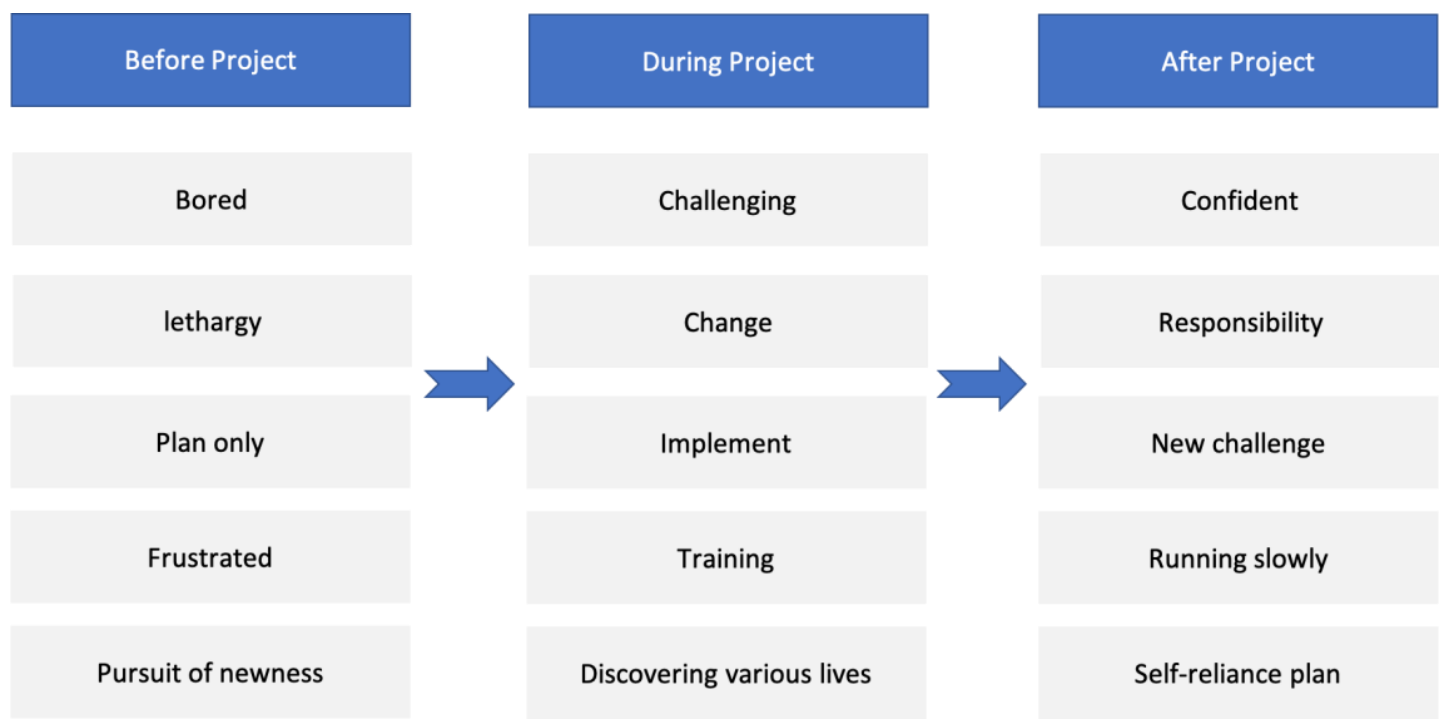

Fig. 4. Self-perception of participants' psychological state during the project

The results of this study shed light on the key psychological values that participants gained through the project. First, as participants were immersed in the activities, they perceived a recovery in their confidence and their sense of belongingness as the greatest outcomes of the project. In view of previous research that highlight decreased self-confidence and increased depression as the common expressions of negativity of the NEET, the project reveals that participation and reciprocal communication in engaging in daily and routine activities effectively engender the psychological affirmation that the NEET need.

Among the eleven values assessed by interviewees, nine values scored greater than four points (out of seven) on the Likert scale. In this regard, setting a daily mission influences personal factors such as immersion, confidence, routine, goal, viewpoint and responsibility, while reciprocal communication among participants triggers relational factors including belongingness, social support, and new relationship. On account of social exclusion which is a key concern that researchers focus on for the NEET, it is suggested that interaction with other members of the community is necessary for the social inclusion of the NEET.

Relatively, it seems that the personal and relational are not mutually exclusive areas. However, high incloseness network scores of "Responsibility (0.513)," and "Social Support (0.531)" suggest that these values are closely related to other values. As the network diagram in Fig. 3 depict, the value of social support is highly related to the responsibility value, and the more responsibility the participants feel, the greater they are inclined to set goals, which eventually increases their desire for a job. 
At first glance, the results for the "Desire for Job" seem unsatisfactory as it records the lowest score $(M=3.79)$ among the eleven identified values and especially as the ultimate aim of this study is to contribute to increasing the employment rate. However, the eigenvector network score for "desire for job" records the highest score of 0.854 . This suggests that although not all identified values are related to the "Desire for Job" and this project does not directly result in participants' motivation for a job, other values such as goal, viewpoint or confidence may function as a mediator. In other words, participation in the project activities and communication with other participants primarily influence other values. Following, the increase in values stimulate mediating values, goal, viewpoint and confidence, and ultimately, affect the "Desire for Job".

The overall results confirmed the importance of psychological factors as one of the measures to resolve unemployment problems as precious researches claimed. Youth NEET is a deep-rooted problem in our society. In particular, recent statistics depict that the share of highly educated and older unemployed people is growing. In addition, in hand with the economic downturn, the number of "non-job seekers" and "abandoned" NEETs who are no longer seeking jobs is increasing [29]. The rise in the number of involuntary NEET suggests that the current policies, such as providing technology assistance and information on job searching, may have its limitations.

Therefore, many researchers acknowledge the need for measures that address the NEET phenomenon in our society to centered upon on factors regarding individual career obstacles, and not merely on the imbalance of the labor market. As aforementioned, overcoming psychological obstacles such as confidence and self-esteem is another variable that may solve the youth unemployment problem.

This study aims to derive policy implications in addressing the youth unemployment problem on the individual level in view of the insufficient research examining the psychological factors in devising a solution. Therefore, the implications derived from this study are as follows;

First, we need to provide means to engage young people in routine activities targeting the opportunity-seeking and abandoning NEETs who make up most of NEET population in Korean society. Civic engagements where NEETs can exchange communication and emotion with other people can prevent them from being isolated from the society.

Second, it is necessary to provide a public sphere for the NEET in our society to exchange information and communication. The biggest motivation behind successful completion of the 100-day project reviewed in this study was the encouragement and support shared among participants and the increased sense of responsibility. Such social networks can also provide opportunities to align people's careers to their interests by sharing diverse experiences and life goals.

Third, changes in daily routines and social communication allow participants to adopt new goals and gain newfound confidence. During the interviews, the interviewees mentioned that they gained the confidence to achieve new goals through the completion of the project. They stated that even if the goals they set while completing the project were not directly linked to their job search activities, establishing healthy and regular routines and building confidence made it easier for them to achieve certain job search goals.

The Kakao NEET project stimulated motivation and confidence in the NEET, an isolated group of the society. This suggests that digital enterprises may indeed utilize their services as a tool in contributing to society, highlighting avenues for future research. This also provides implications for the private sector, as digital or B2C (Business to Consumer) enterprises in particular, may achieve corporate sustainability goals such as ESG (Environmental, Social and 
Governance) by using their digital services as a platform for the social good.

\section{References}

[1] M. Park, "A study on the determinants of youth NEETs in OECD countries: The moderating effect of social policies and industrial shift," Quarterly Journal of Labor Policy, vol. 17, no. 3, pp. 1-44, 2017. Article (CrossRef Link)

[2] S. Cha, "Differentials in daily lives of NEETs in Korea: Implications to studies on transition to adulthood," Family Relations Study, vol. 19, no. 2, pp. 75-95, 2014. Article (CrossRef Link)

[3] H. Pang and S. Yoo, "Korean newspapers and discourses on the young generation (from silk generation to sampo generation): Walking a tightrope between crisis theory and the theory of hope," Korean Journal of Journalism \& Communication Studies, vol. 59, no. 2, 37-61, 2015.

Article (CrossRef Link)

[4] Korea Enterprises Federation, "2014 survey on wage adjustment," [online]. Available: http://www.fki.or.kr/Common/Download.aspx?id=2bedd428-192b-4e47-9df0-f67ee898f1b4

[5] Korea Economic Research Institute, "Unemployment rate for youth college graduates fell from 14th to 28th in the OECD ranking for 10 years," 2020. Article (CrossRef Link)

[6] J. Nam, "Research on youth NEET and middle age NEET," pp. 239-258, 2019. Article (CrossRef Link)

[7] Social Exclusion Unit, "Bridging the gap: new opportunities for 16-18 year olds not in education, employment or training," The Stationery Office, 1999. Article (CrossRef Link)

[8] R. Thompson, "Individualisation and social exclusion: the case of young people not in education, employment or training," Oxford Recview of Education, vol. 37, no. 6, pp. 785-802, 2011. Article (CrossRef Link)

[9] A. Powell, "NEET: Young people not in education, employment or training," House of Commons Library: Briefing Paper, 2018. [online] Available: https://researchbriefings.files.parliament.uk /documents/SN06705/SN06705.pdf

[10] J. Nam, "The current status and trend of youth NEET," Labor Review, pp. 29-40, 2011. Article (CrossRef Link)

[11] H. Chu, "An analysis of job adjustment barriers of new college graduates," The Korean Journal of Human Resource Development Quarterly, vol. 14, no. 1, pp. 73-93, 2012. Article (CrossRef Link)

[12] S. Kim, "Young people not in education, employment or training in the UK and South Korea: Comparative evidence from the PIAAC," Studies on Korean Youth, vol. 30, no. 1, pp. 185-217, 2019. Article (CrossRef Link)

[13] J. Kum, Y. Jeon, and J. Cho, "An economical study of Korean youth unemployment through the concept of Korean NEET," Seoul, Korea: Korea Employment Information Service, 2007. Article (CrossRef Link)

[14] OECD, Society at a glance: Asia/Pasific, 2019. Article (CrossRef Link)

[15] R. Lee, K. Park, and Y, Chung, "A qualitative study on the classification of NEETS in the labor market: characteristics and implications," The Journal of Career Education Research, vol. 23, no. 1, pp. 153-175, 2010. Article (CrossRef Link)

[16] Eurofound, "Young people and NEETs in Europe: First finding," Dublin, Ireland: Eurofound, 2012. Article (CrossRef Link)

[17] H. Joo, and H. Joo, "A Study on the Types and Characteristics of Young Unemployed in Korea," Korean Public Personnel Administration Review, vol. 16, no. 2, pp. 51-73. 2017. Article (CrossRef Link)

[18] D. Cho, E. Kim, K. Kim, and H. Jeong, "Classification of the Koran youth NEET with higher education and measures to escape from the state of NEET," Journal of Competency Development \& Learning, vol. 13, no. 2, pp. 165-190, 2018. Article (CrossRef Link)

[19] J. Kim and E. Park, "The effects of achievement type of developmental tasks of early adulthood on the perceived social isolation in youth," Studies on Korean Youth, vol. 27, no. 3, pp. 257-284, 2016. Article (CrossRef Link) 
[20] R. K. Merton and P. L. Kendall, “The focused interview," American Journal of Sociology, vol. 51, no. 6, pp. 541-557, 1946. Article (CrossRef Link)

[21] M. Kane and W. M. Trochim, Concept mapping for planning and evaluation, Thousand Oaks, CA, USA: Sage Publications, 2007. Article (CrossRef Link)

[22] N. Nurmuliani, D. Zowghi, and S. P. Williams, "Using card sorting techniques to classify requirements change," in Proc. of the $12^{\text {th }}$ IEEE International Requirements Engineering Conference, pp. 240-248, 2004. Article (CrossRef Link)

[23] G. Rugg and P. McGeorge, "The Sorting Techniques: ATutorial Paper on Card Sorts, Picture Sorts and Item sorts," Expert Systems, vol. 22, no. 3, pp. 94-107, 2005. Article (CrossRef Link)

[24] D. E. Zimmerman and C. Akerelrea, "A Group Card Sorting Methodology for Developing Informational Web Sites," in Proc. of International Professional Communication Conference (IPCC), pp. 437-445, 2002. Article (CrossRef Link)

[25] S. P. Borgatti and M. G. Everett, "Models of core periphery structure," Social Networks, vol. 21, no. 4, pp. 375-395, 2000. Article (CrossRef Link)

[26] Y. Jung, S. D. Pawlowski, and S. Wiley-Patton, "Conducting social cognition research in IS: A methodology for eliciting and analyzing social representations," Communications of the Association for Information System, vol. 24, no. 35, 2009. Article (CrossRef Link)

[27] J. Ahn and Y. Jung, "The common sense of dependence on stamrtphione: A comparison between digital natives and digital immigrants," New Media and Society, vol. 24, pp. 1-21, 2014. Article (CrossRef Link)

[28] H. Noh and Y. Kim, "The major characteristics and impact factors of NEET youth in Korea: AN analysis of population groups by level of education," Journal of Public Society, vol. 9, no. 4, pp. 73-105, 2019. Article (CrossRef Link) 


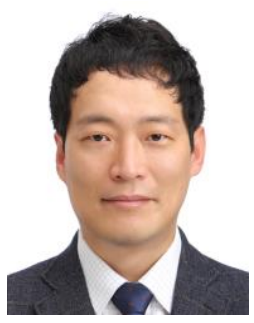

Jaekwan Jeong received his Ph.D. in Communication at Konkuk university. Prior to working at Kakao policy team, he had been teaching at SUNY Plattsburgh. His research interests include digital media, ICT industry, audience effects and social capital.

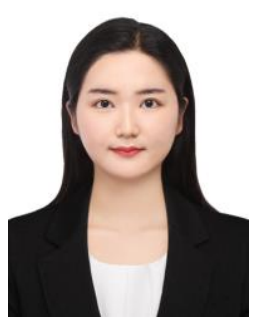

Kahui Park received her B.A. degree in economics from Yonsei University in 2021. Her research interests include AI ethics and platform governance.

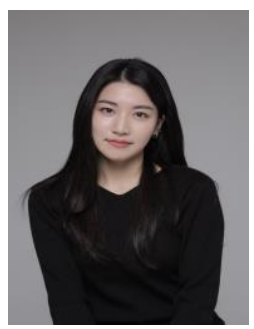

Yaewon Hyun received her B.A. in International Studies at Ewha Womans University. She is pursuing a M.A. in International Development Cooperation at the Graduate School of International Studies at Ewha Womans University. Her research interests concern ICT4D and digital development. Currently, she is involved in technology policy research at the Policy Team of Kakao Corp.

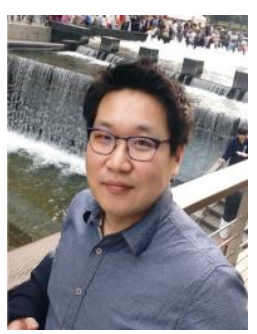

Daewon Kim received his $\mathrm{PhD}$ degree at the School of Media Communication of Korea University, where he focused on robotic journalism. He worked as a journalist for about 10 years. His research interests include robotic journalism, diffusion of artificial intelligence, mobile media, media business, media strategy, and entertainment business. Since May 2018, he serves as the director of policy team at Kakao. 